九州大学学術情報リポジトリ

Kyushu University Institutional Repository

\title{
Investigating Variation of Dynamic Frictional Effect of Different Textile Fabrics Against Dry and Wet Human Skin Condition at a Fixed Load
}

Shadman Sakief Hridoy

Department of Mechanical Engineering, Bangladesh University of Engineering and Technology

Azim, Ehsanul

Department of Mechanical Engineering, Bangladesh University of Engineering and Technology

Md. Jahid Hasan Sagor

Department of Mechanical Engineering, Bangladesh University of Engineering and Technology

Abde lhamid, Talaat

Center for Turbulence and Control, Harbin Institute of Technology (Shenzhen)

https://doi.org/10.5109/4738575

出版情報: Proceedings of International Exchange and Innovation Conference on Engineering \& Sciences (IEICES). 7, pp. 109-115，2021-10-21. 九州大学大学院総合理工学府

バージョン:

権利関係: 


\title{
Investigating Variation of Dynamic Frictional Effect of Different Textile Fabrics Against Dry and Wet Human Skin Condition at a Fixed Load
}

\author{
Shadman Sakief Hridoy ${ }^{1}$, Ehsanul Azim ${ }^{1}$, Md. Jahid Hasan Sagor ${ }^{1}$, Talaat Abdelhamid ${ }^{2,3,4 *}$ \\ ${ }^{1}$ Department of Mechanical Engineering, Bangladesh University of Engineering and Technology, Bangladesh \\ ${ }^{2}$ Center for Turbulence and Control, Harbin Institute of Technology (Shenzhen), Shenzhen 518055, China. \\ ${ }^{3}$ Shenzhen Institutes of Advanced Technology, Chinese Academy of Sciences, Shenzhen 518055, China. \\ ${ }^{4}$ Physics and Mathematical Engineering Department, Faculty of Electronic Engineering, Menoufiya University, Menouf \\ 32952, Egypt. \\ ${ }^{*}$ Corresponding author email: talaat_abdelhamid@el-eng.menofia.edu.eg
}

\begin{abstract}
The principal focus of this experiment was to investigate the dynamic friction properties of different fabric samples at dry and wet skin conditions for a fixed load. The experiment was done by a simple setup with fabric sliding mechanism over human skin for four separate fabric samples of two different categories. Friction forces between different fabrics and human skin were measured through the experimental procedure and afterwards friction coefficient was calculated using Capstan formula from the obtained value of force. It was observed that the friction coefficient of Garment fabrics is lower than that of Special fabrics in dry condition. Wet condition resulted in higher frictional effects than dry condition of the skin providing perfect matching of natural frictional characteristics of any surface. Besides, the wetness of skin, as well as wettability of fabrics, also have a significant influence on the friction coefficient.
\end{abstract}

\section{INTRODUCTION}

Friction is a major determinant of product quality and fabric processing efficiency in the textile industry. Due to the wide range of applications, textile friction must be measured using a variety of test methods. The type of textile material, the contact between the surfaces, the surrounding environment of the contact zone, and the methods for beginning the relative motion are all variables that affect these procedures. Regardless of the type of textile material employed, contact between two fabrics or one fabric and another surface happens.

In the early 1980s, the influence of skin humiture on the perception of fabric texture and pleasantness were investigated.Gwosdow, et al. [1] determined friction between fabric and human skin through measurement by a simple 'Tensometer' under various environmental conditions: neutral (comfortable), hot-dry and hot-humid. Later in the 1990s, Kenins [2] also investigated the influence of moisture, fiber type and fabric construction parameters on the friction properties between fabric and skin by a similar method. Subsequently,friction coefficient was proposed to describe the friction properties between fabric material and human skin. Zhang and Mak [3] proposed a method for measuring friction coefficient between various fabric materials and individual skin by a small piece of fabric sample that was pasted on the contactor of friction tester before testing. In other studies, some elastic materials such as silicone were applied as mechanical skin equivalent to rub with fabric. Bertaux, et al. [4] measured the friction between such type of artificial skin and fabric by traditional friction tester.

The human sensory system's outermost portion, the skin, functions as a force transmitter and a sensor in connection with the environment. Human skin, on the other hand, spends the majority of its time in intimate contact with various fibers in clothing and textiles. Recently many researchers proposed various solutions regarding medical textiles for decubitus ulcers prevention [5-8].Numerous factors influence the friction coefficient between human skin and clothes, including humidity, hydrophobicity [9], the fabric itself, and, of course, the skin's characteristics. Ramalho et al.[10] suggested that friction is an important factor in the pleasant feeling produced when touching an object, especially garments. Additionally, it also plays an important role in skin contact injuries.

Therefore, in this study, our major concern has been to investigate the correlation between tactile perception and friction. For this reason,four typical fabrics of different textile fiber have been dynamically run over human hand skin at various skin condition to get a good comparison among those conditions. We also have investigated the tentative reasons for the outcomes and have discussed the reasons of some deviations.

\section{EXPERIMENTAL SETUP}

The schematic description of the present study has been shown in Fig.1. In this setup, a fabric sample slides across a human skin (forearm). A fixed weight of $20 \mathrm{~g}$ is suspended from one end of the fabric to apply pressure between fabric and skin. The other end of the fabric is attached to a load cell mounted on a slider, which is pulled horizontally along two drawer channels by a $12 \mathrm{~V}$ DC motor. The linear speed of fabric pulled across the skin was nearly $1.97 \mathrm{~cm} /$ second. An amplifier and an Arduino board are connected with the load cell which generate the experimental data on a computer screen. 


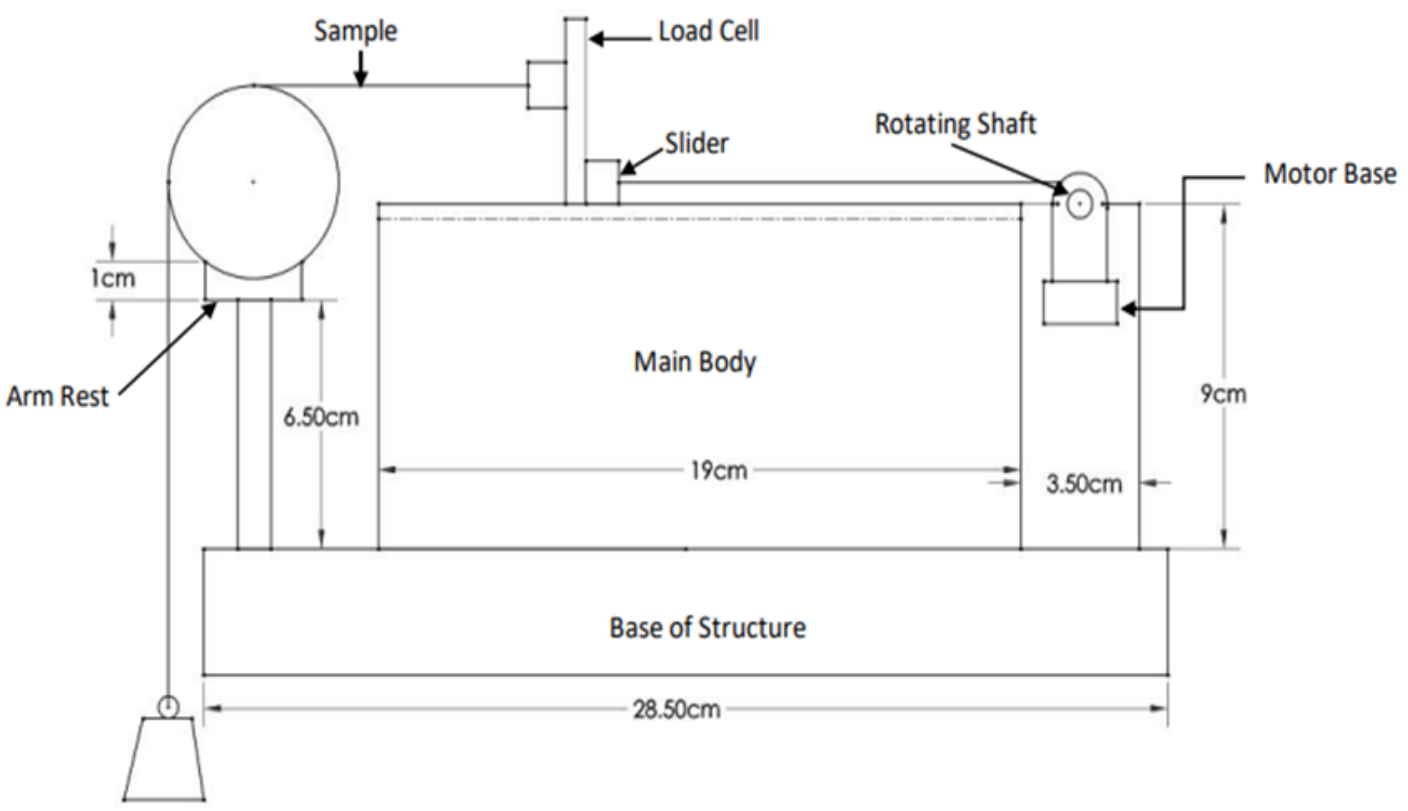

Fig.1: Schematic diagram of the experimental setup

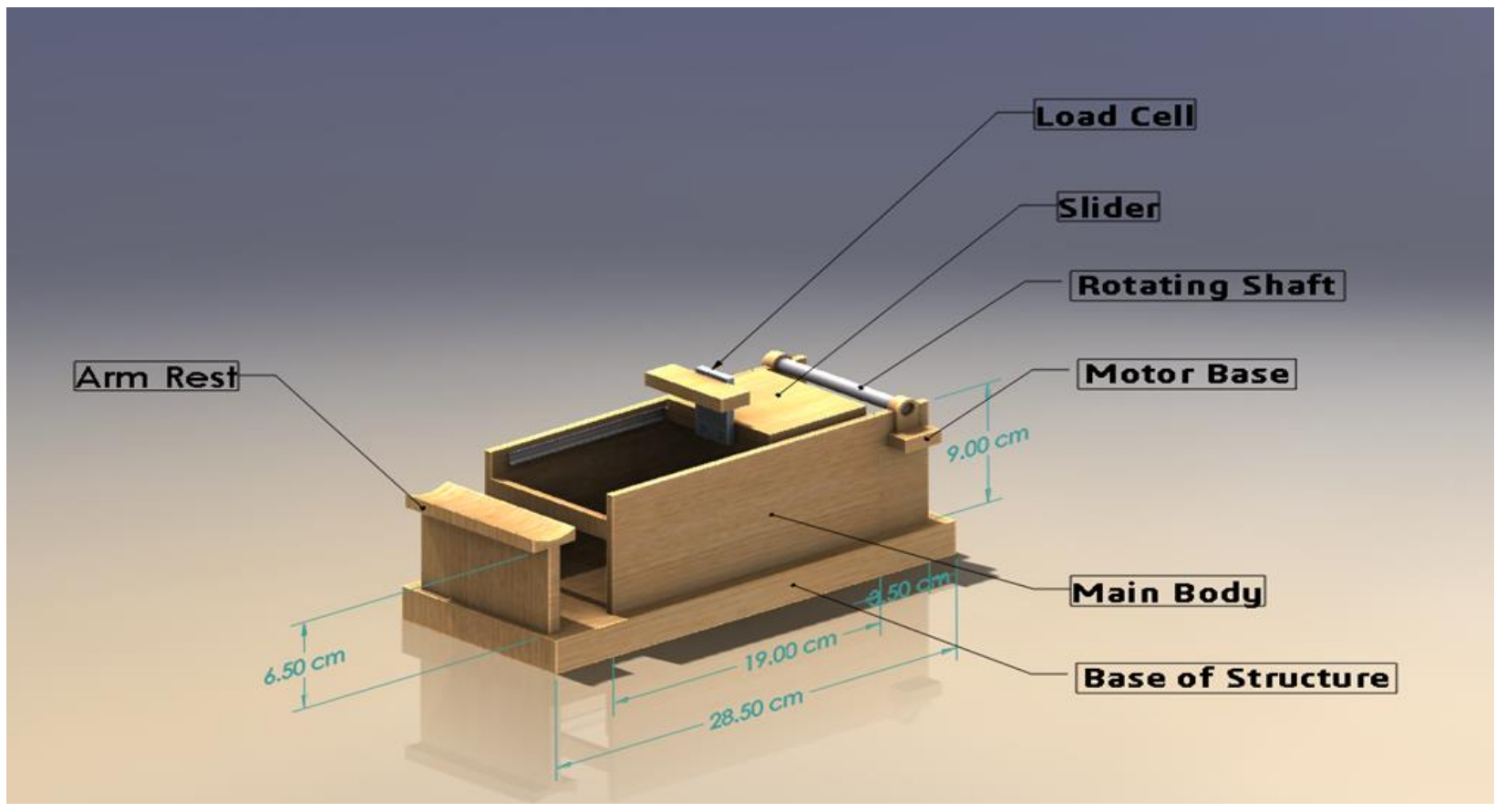

Fig.2: $3 \mathrm{D}$ scenario of the setup

\section{SAMPLE SPECIFICATION}

Four different samples were used in this study which can be categorized into two major groups:

\section{- Garment Fabrics}

-Print Z Twill (35\% cotton+65\% polyester, $0.233 \mathrm{~g} / \mathrm{cm})$

-Denim Z Twill (100\%cotton, $0.423 \mathrm{~g} / \mathrm{cm}$ )

\section{Special Fabrics}

-Plain Tent $(100 \%$ cotton, $0.387 \mathrm{~g} / \mathrm{cm})$

-Steppe Plain ( $35 \%$ cotton $+65 \%$ polyester, $15.08 \mathrm{~g} / \mathrm{cm})$ 
Table 1. Properties of the different fabrics used in the experiment

\begin{tabular}{|l|l|l|l|l|l|l|}
\hline $\begin{array}{l}\text { Sample } \\
\text { No }\end{array}$ & $\begin{array}{l}\text { Sample } \\
\text { name }\end{array}$ & $\begin{array}{l}\text { GSM } \\
\text { (gram } \\
\text { per } \\
\text { square } \\
\text { meter) }\end{array}$ & $\begin{array}{l}\text { EPI } \\
\text { (ends } \\
\text { per } \\
\text { inch) }\end{array}$ & $\begin{array}{l}\text { PPI } \\
\text { (pick } \\
\text { inch) }\end{array}$ & Warp & Weft \\
\hline 01 & $\begin{array}{l}\text { Print Z } \\
\text { Twill }\end{array}$ & 222 & 72 & 112 & 20 & 19 \\
\hline 02 & $\begin{array}{l}\text { Denim } \\
\text { Z Twill }\end{array}$ & 437 & 41 & 18 & 9 & 6 \\
\hline 03 & $\begin{array}{l}\text { Plain } \\
\text { Tent }\end{array}$ & 377 & 80 & 44 & 44 & 22 \\
\hline 04 & $\begin{array}{l}\text { Steppe } \\
\text { Plain }\end{array}$ & 214 & 112 & 60 & - & - \\
\hline
\end{tabular}

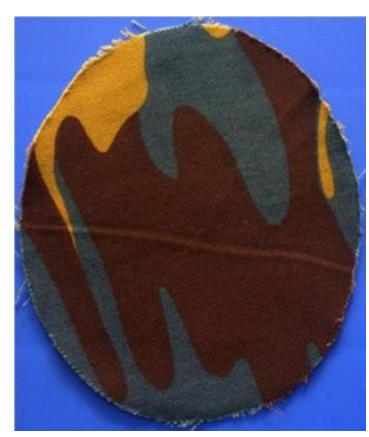

(a)

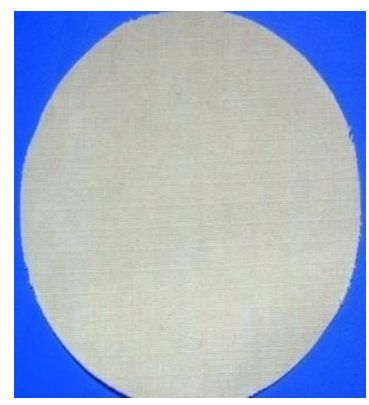

(c)

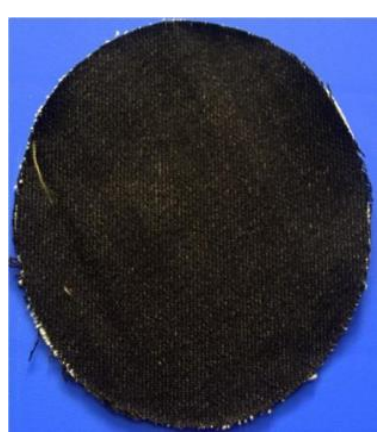

(b)

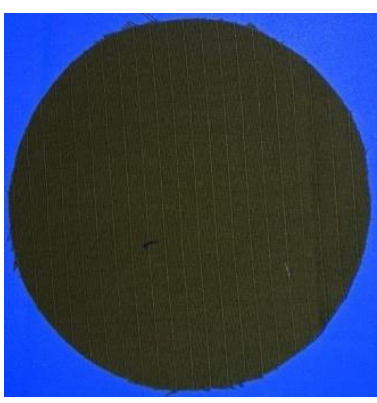

(d)
Fig.3:Four samples: (a) Print Z Twill (b) Denim Z Twill (b) Plain Tent (d) Steppe Plain

\section{MATHEMATICALFORMULAE \& METHODS}

For the friction measurement, we used Capstan's Formula.

\subsection{Capstan Method:}

In this experiment,the textile fabric samples are pulled over a human hand's forearm which is approximated as a cylindrical body. As a result, a rolling friction force is generated between the fabric and a cylindrical surface due to the normal force $\mathrm{N}$ generated by the tension $\mathrm{T}_{1}$ and $\mathrm{T}_{2}$ exerted on the ends of the fabric.

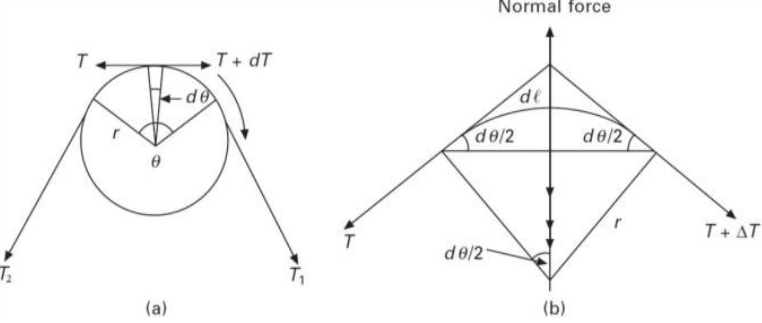

Fig.4: (a) Schematic diagram of the Capstan Method(b)Evaluation of forces in a small element [11]

A contact angle $\boldsymbol{\theta}$ is considered at a portion of the curved surface of the cylinder over which the contact occurs. A small contact angle $\boldsymbol{d} \boldsymbol{\theta}$ is also taken into accountin Fig. 4 due to which the tensions $\boldsymbol{T}$ and $\boldsymbol{T}+\boldsymbol{d} \boldsymbol{T}$ on the ends of the element can be used to calculate the value of the normal force as follows:

$$
d N=T \sin \frac{d \theta}{2}+(T+d T) \sin \frac{d \theta}{2}
$$

Since $d \theta$ is very small, $\sin \frac{d \theta}{2} \approx \frac{d \theta}{2}$, and $d T \sin \frac{d \theta}{2}$ being a negligible term, the equation becomes:

$d N \approx T d \theta$

As the frictional drag causes the increase in tension, $\boldsymbol{d T}$ the classical equation of friction can be written as:

$d T=\mu d N$, or $d T=\mu T d \theta$

By integration in the above equation using appropriate limits the following well-known expression can be derived:

$T_{1}=T_{2} e^{\mu \theta}$

This equation justifies that there is no effect of the size of the cylinder on the rolling friction force. So, our consideration of the human forearm as a static cylinder over which the sample fabrics were slid does not incorporate any notable deviation in the experimental results.

\subsection{Determination of suspended load:}

Two types of loads were used to calculate the friction coefficient in this study. One was pulling load $\left(T_{1}\right)$ measured by the load cell and another was the suspended load including the weight of fabrics used. As the slider moved forward, the suspended length of fabrics decreased. As a result, the total suspended load $\left(\mathrm{T}_{2}\right)$ also changed. So, the suspended load was measured by developing the following expression:

$T_{2}=m+m_{1}(L-1.97 t)(5)$

where, $\boldsymbol{T}_{2}=$ total suspended load $(\mathrm{g})$

$\boldsymbol{m}=$ suspended length mass of sample fabric $(\mathrm{g})$

$\boldsymbol{L}=$ total length of sample fabric $(\mathrm{cm})$

$\boldsymbol{t}=$ time $(\mathrm{sec})$

$\boldsymbol{m}_{\boldsymbol{1}}=$ sample fabric mass per unit length $(\mathrm{g} / \mathrm{cm})$ 


\section{EXPERIMENTAL PROCEDURE}

The experimental setup was placed on a rigid place. The setup needs to be stable while running the experiment. At first, the forearm was placed correctly on the armrest and the slider was set on starting position. Then one of the sample fabrics to be tested was attached with the slider and positioned carefully over the forearm. A known mass or load was suspended to another end of the sample. Then the motor was switched on and the shaft started rotating. A fabric belt was used to convert shaft's rotating motion into linear motion of the slider. The motor was kept on until the slider reached to the ending position. Whenever it reached the ending point,the motor was switched off. The sliding time was recorded with the help of stopwatch earlier. The reading for the horizontal forces, measured with the help of load cell, was taken out at two-second interval up to the time required to slide the sample from starting position to ending position. All of the data were collected from a computer screen that was generated by the amplifier and Arduino board. Finally using the data friction coefficient was measured by Capstan Equation.

The same steps were done repeatedly for a particular test condition. The test conditions were changed by using various combination of samples, suspended loads, different skin conditions and different humidity.

\section{RESULTS AND DISCUSSIONS}

From the current experimental output data of dynamic friction coefficient with respect to time it is clearly observed that each of the 4 samples have common characteristics of achieving higher friction force in wet condition than that of dry condition. But in case of wet condition, we also considered two different materials for wetting the human skin: water and body lotion. These two conditions result variation in friction values in every sample. For this reason, here we analyze the 3 conditions (dry, water and Body lotion) individually for the 4 samples:

\subsection{Comparison of friction in dry condition:}

According to Fig.6 among the four samples the two special fabrics (Plain Tent and Steppe Plain) experienced more friction than the garment fabrics. The main reason behind it is the texture of the weave of special fabrics. In plain weave warp fibers are passed alternately under and over the weft fibers which results in excessive fiber crimps and lessen the mechanical properties of the fabrics. Consequently, the roughness of the surface of the fabric is higher than the other types of fabrics. So, the friction becomes higher when the fabrics were slid over human forearm skin. On the other hand, in twill weave, one or more warp fibers are passed successively over and under two or more weft fibers in a regular repeated manner [12].

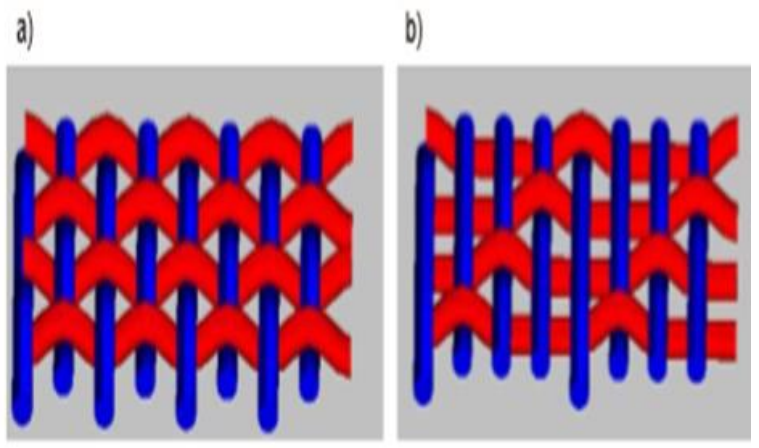

Fig.5: Weave design (a)Plain weave(b) Twill weave [13]. Here the red fibers denote the weft fibers, and the blue fibers denote the warps.

It results in a small reduction of the fabric's durability but with reduced crimp, the fabrics also have smoother surface and slightly higher mechanical properties [12].

Here we also found that (Fig. 6) Steppe Plain fabric has the highest amount of frictional effect and it increases higher with time in spite of having some fluctuations since the fabric did not pass over the skin smoothly and got stuck somewhere on the skin surface. This phenomenon is called Stick-Slip phenomenon (SSP). It is highly observed in the case of Plain Tent fabric which experienced two limiting values of friction coefficient in both increasing and decreasing manner. Conversely, the Print Z Twill fabric showed approximately steady frictional effect since its roughness is comparatively lower than the plain fabrics and it results lower friction coefficient with a very little fluctuation. Among all the fabrics Denim Z Twill resulted the lowest frictional effects over the skin but it could not continue the approximate steadiness of the friction coefficient till the last experimental time. Rather the value of friction coefficient gradually increased from $8 \mathrm{sec}$. Actually, in Denim Z Twill fabric the twill weave is formed by heavy cotton fiber with the warp thread being dyed whereas the weft threads are kept white. It results a density difference between warp and weft fibers that can increase the surface roughness. In the experiment, at first 8 seconds, the roughness was not significant which made the frictional effects steady but after 8 seconds passed, the fabric surface increased continuous contact with skin which resulted gradual increasing of friction coefficient and it increased approximately to 0.44 and afterwards there was also a decrement of friction here due to SSP. 


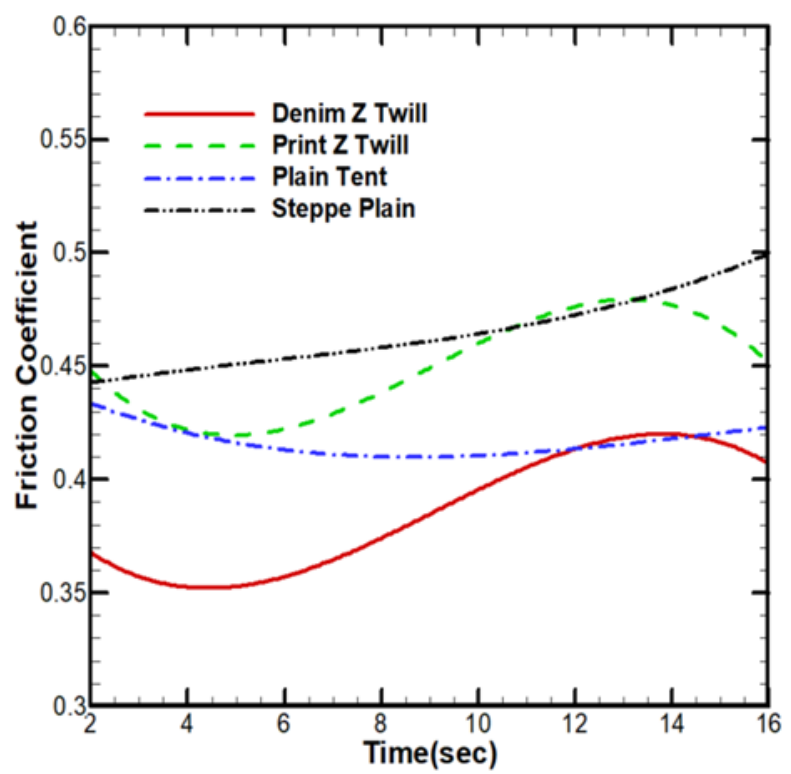

Fig. 6: Variation of friction of the sample fabrics with respect to time at dry condition.

\subsection{Comparison of friction in wet (water) condition:}

In wet (water) condition, though the friction naturally increased higher than dry condition for all types of fabrics, the consequences of each fabric was not similar as dry condition. In Fig.7, we can see that in the case of water-wet condition Print $\mathrm{Z}$ Twill showed the highest frictional effect which is very much higher than the other 3 samples. It means that Print $\mathrm{Z}$ Twill has the highest wettability among all the 4 sample fabrics that results high adhesion of water with the fabric surface and the friction automatically went higher (0.87-0.95). The other 3 sample fabrics have higher absorptivity than Print $\mathrm{Z}$ Twill that resulted in their friction coefficient increment at a very small rate. Due to the highest absorptivity, Denim Z Twill again resulted lowest friction behavior through reducing water content on wet human skin. Though the two special fabrics: Plain tent and Steppe Plain experienced higher frictional effect in water-wetted condition (0.71-0.76), these fabrics have lower friction in comparison with Print $\mathrm{Z}$ Twill for having lower absorptivity of water, but they also do not achieve so much absorptivity as like Denim Z Twill. So, the special fabrics behave like medium absorbent of water among these fabrics.

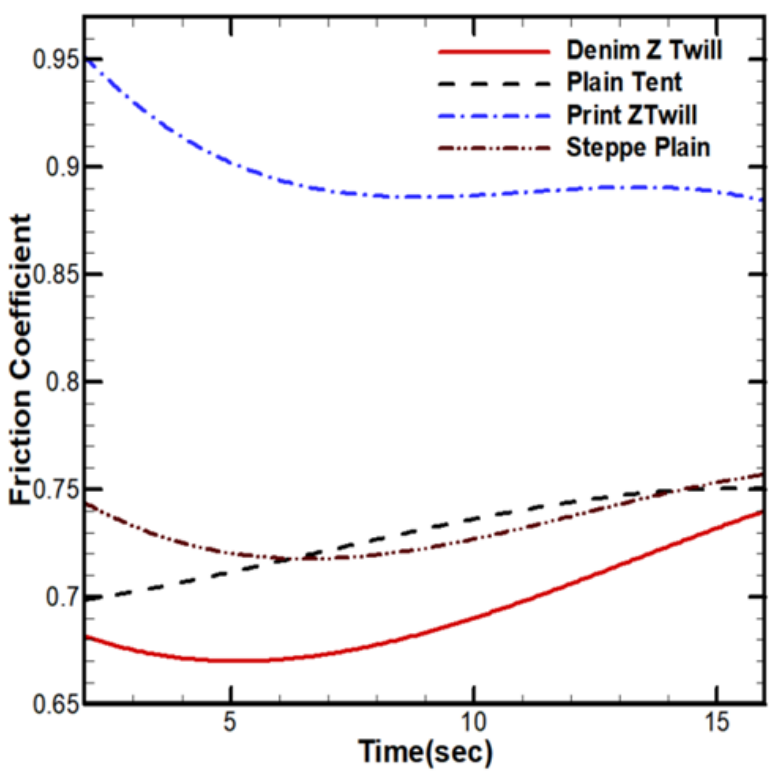

Fig.7: Variation of friction of the sample fabrics with respect to time at wet (water) condition.

\subsection{Comparison of friction in wet (body lotion) condition:}

Body lotion was considered here as another fluid material for wet condition of the skin. That is why it was expected to have almost similar outcome like water-wetted condition. But surprisingly there occurred a large variation in friction behavior of the fabrics except for Print Z Twill. From Fig.8 it can be easily seen that Print $\mathrm{Z}$ Twill had higher friction than the other 3 samples in this case too though the friction coefficient was less than the water-wetted condition. Since body lotion consists of a considerable percentage of lubricant, its viscous effect is reduced highlywhich results lower friction than water. In case of Print Z Twill, when the fabric was slid over the wetted hand skin with body lotion, with gradual sliding the fabric got wetted by lotion and due to its lubrication properties, it filled the fabric surface with lubricant layer resulting in smoother wetted surface. As a result, Print $\mathrm{Z}$ Twill experienced lower friction coefficient (0.85-0.87) than the water-wetted condition. 


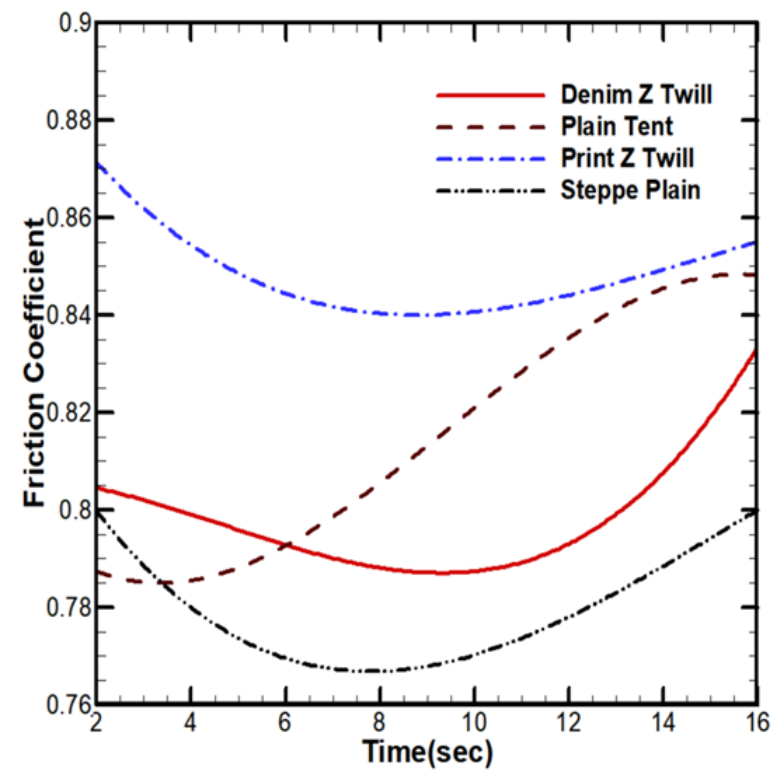

Fig.8: Variation of friction of the sample fabrics with respect to time at wet (body lotion) condition.

In contrast with Print $\mathrm{Z}$ Twill, all the other 3 sample fabrics resulted higher friction coefficient on an average in body lotion-wetted condition than that of water-wetted condition. Adhesion of lotion can be a good reason behind this exception of the 3 samples because, for any wetted body which can be wetted by any fluid, the higher adhesive force plays the greatest role for increasing friction of the body surface. In wet condition with body lotion, another surprising phenomenon was the lowest friction behavior of Steppe Plain fabric whereas in the other two conditions it had greater frictional effect than most of the fabrics considered here. We think that Steppe Plain also showed here almost similar behavior like Print $\mathrm{Z}$ Twill in this condition. Body lotion's lubricant properties drastically reduced the Stick-Slip Phenomenon of this fabric.Thus, here itresultedthelowest friction among all the fabrics.

Last but no the least, we can show the average friction properties of the four fabrics in the 3 different conditions in a bar chart as follows:

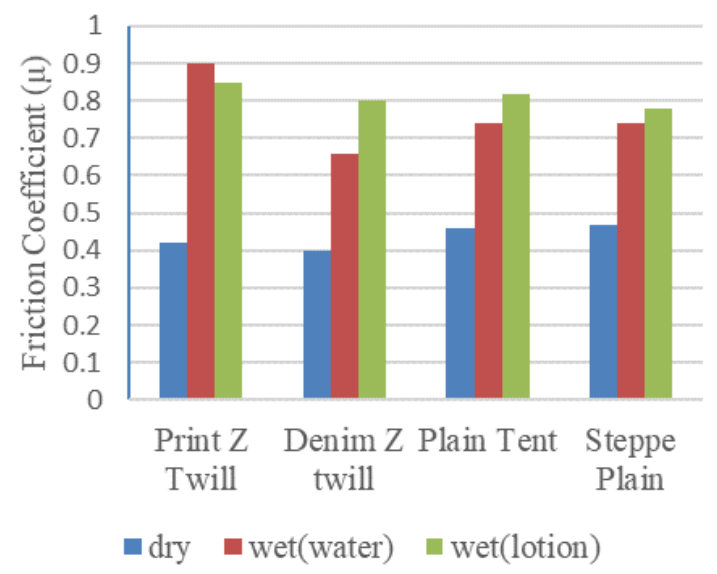

\section{CONCLUSION}

This experimental study was mainly concerned with comparing the frictional effects of various types of textile fabrics against human skin in 3 different conditions (dry, water-wet, lotion-wet) at a fixed tensile load of $20 \mathrm{~g}$. Here fabric friction was greatly influenced with some parameters: the texture of weave of the fabrics, surface conditions of the skin (dry, wet), wetting material's properties. Based on the obtained results from the present study some decisions can be mentioned in brief:

(a) Fabrics' warp and weft thread texture have a significant role in surface friction.

(b) Wettability and absorptivity of any fabric surface determine frictional effects greatly in wet conditions.

(c) Material's viscosity, adhesion etc. are also important properties for estimating friction of the fabric surface against human skin in wet conditions.

\section{REFERENCES}

[1] Gwosdow, A. R., J. C. Stevens, L. G. Berglund, and J. A. J. Stolwijk. "Skin friction and fabric sensations in neutral and warm environments." Textile Research Journal 56, no. 9 (1986): 574-580.

[2] Kenins, P. "Influence of fiber type and moisture on measured fabric-to-skin friction." Textile Research Journal 64, no. 12 (1994): 722-728.

[3] Zhang, Ming, and A. F. T. Mak. "In vivo friction properties of human skin." Prosthetics and orthotics International 23, no. 2 (1999): 135-141.

[4] Bertaux, Emilie, Maryline Lewandowski, and Siegfried Derler. "Relationship between friction and tactile properties for woven and knitted fabrics." Textile Research Journal 77, no. 6 (2007): 387-396.

[5] Rotaru, G-M., D. Pille, F. K. Lehmeier, R. Stämpfli, A. Scheel-Sailer, R. M. Rossi, and S. Derler. "Friction between human skin and medical textiles for decubitus prevention." Tribology International 65 (2013): 91-96.

[6] Pryczynska, E., Barbara Lipp-Symonowicz, Andrzej Wieczorek, W. Gaszynski, Katarzyna Krekora, and E. Bittner-Czapinska. "Sheet fabrics with biophysical properties as elements of joint prevention in connection with first-and second-generation pneumatic anti-bedsore mattresses." FIBRES AND TEXTILES IN EASTERN EUROPE 11, no. 4 (2003): 50-53.

[7] Smith, G., and A. Ingram. "Clinical and cost effectiveness evaluation of low friction and shear garments." Journal of wound care 19, no. 12 (2010): 535-542.

[8] Zhong, Wen, Ayyaz Ahmad, Malcolm MQ Xing, Pat Yamada, and Carole Hamel. "Impact of textiles on formation and prevention of skin lesions and bedsores." Cutaneous and ocular toxicology 27, no. 1 (2008): 21-28.

[9] Gerhardt, L-C., V. Strässle, A. Lenz, Nicholas D. Spencer, and Siegfried Derler. "Influence of epidermal hydration on the friction of human skin against textiles." Journal of the Royal Society Interface 5, no. 28 (2008): 1317-1328. 
[10] Ramalho, A., P. Szekeres, and E. Fernandes. "Friction and tactile perception of textile fabrics." Tribology International 63 (2013): 29-33.

[11] Gupta, Bhupender S., ed. Friction in textile materials. Elsevier, 2008.

[12]http://www.Netcomposites.com/guide/reinforcemen ts/woven-fabrics/

[13] Azeem, Musaddaq, Zuhaib Ahmad, Jakub Wiener, Ahmad Fraz, Hafiz Faisal Siddique, and Antonin Havalka. "Influence of weave design and yarn types on mechanical and surface properties of woven fabric." Fibres \& Textiles in Eastern Europe (2018). 